\title{
Procedural Change in the UK House of Commons,
}

\section{$1811-2015$}

\author{
Niels D. Goet ${ }^{\dagger} \quad$ Thomas G. Fleming ${ }^{\ddagger} \quad$ Radoslaw Zubek $^{\S}$
}

\begin{abstract}
Recent research has shown an increasing interest in the historical evolution of legislative institutions. The development of the United Kingdom Parliament has received particularly extensive attention. In this paper, we contribute to this literature in three important ways. First, we introduce a complete, machine-readable dataset of all the Standing Orders of the UK House of Commons between 1811 and 2015. Second, we demonstrate how this dataset can be used to construct innovative measures of procedural change. Third, we illustrate a potential empirical application of the dataset, offering an exploratory test of several expectations drawn from recent theories of formal rule change in parliamentary democracies. We conclude that the new dataset has the potential to substantially advance our understanding of legislative reforms in the United Kingdom and beyond.
\end{abstract}

Keywords: Procedural change, legislative rules, UK House of Commons.

*Earlier versions of this article were presented at the 4th Conference of the ECPR Standing Group on Parliaments, 29th June - 1st July 2017, University of Basel, at the research workshop on The Evolution of Parliamentarism and its Political Consequences at the Norwegian Institute in Rome, 14-15 May, 2018, and at the research group on Comparative Institutions and Regimes (CIR) seminar series, Department of Political Science, University of Oslo (8th June 2018). We thank José Antonio Cheibub, Dave Doyle, Reuvan Hazan, Shane Martin, Bjørn Erik Rasch, Meg Russell, Ulrich Sieberer, Tore Wig, Carl Henrik Knutsen, and other participants at these sessions for their insightful critiques and feedback. We would also like to thank three anonymous reviewers and the editor at LSQ for their comments and and suggestions, which have benefited the manuscript greatly. The usual disclaimer applies.

${ }^{\dagger}$ Data Scientist, Inspera AS, Oslo, ndgoet@gmail.com, Corresponding author.

${ }^{\ddagger}$ D.Phil. Candidate, University of Oxford, Department of Politics and International Relations, thomas.fleming@politics.ox.ac.uk.

$\S^{\S}$ Associate Professor of European Politics, University of Oxford, Department of Politics and International Relations, radoslaw.zubek@politics.ox.ac.uk. 


\section{Introduction}

There is much recent interest in the origin and evolution of legislative institutions (Binder 1996, 2006; Fleming 2019; Rasch, S. Martin, and Cheibub 2015; Schickler 2000, 2001; Sieberer, Meißner, et al. 2016; Sieberer, Müller, and Heller 2011; Sin 2015; Spirling 2014; Zubek 2015b). In this paper, we contribute to this research by studying parliamentary reforms in the UK House of Commons. Our primary interest is in the measurement of, and accounting for, the incidence and magnitude of change to the House's procedural rules between 1811 and 2015. During the two hundred years since the early 1800s, the lower chamber of the UK parliament witnessed numerous episodes of significant procedural transformation. While similar developments occurred in other European states, British political development during this period is unique in having occurred in the absence of major disjunctures in the form of regime change, foreign occupation or warfare on British soil. The UK parliament is thus an attractive case for studying procedural change.

There is already a long-standing scholarly debate about procedural change in the UK parliament (Fraser 1960; Redlich 1908). In his seminal contribution, Cox (1987) examined the innovations through which power over the plenary agenda was centralized in the hands of the executive between 1811 and 1867. Dion (1997) analyzed the suppression of minority rights between the adoption of the First Reform Act and the Balfour reforms, while Koß (2015) focused on the events leading to the adoption of closure rules in 1882 and 1887 . Eggers and Spirling (2014) showed how the government consolidated its agenda-setting power in the late nineteenth century by offering the opposition far-reaching inquisitorial powers. The same authors (2018) traced the emergence of the Shadow Cabinet between the First and Fourth Reform Acts. Goet (2019b) studied debate regulation patterns since 1811. Addressing recent developments, Kelso (2009) reviewed parliamentary reforms between 1900 and the early 2000s. Other work has discussed a number of key reforms — the establishment of a select committee system in the 1970s (Jogerst 1993), New Labour's modernization re-

forms (Flinders 2002, 2007), the "Wright reforms" following the 2009 MPs' expenses scandal (Russell 2011), and the introduction of "English Votes for English Laws" (Gover and Kenny 2018). 
We contribute to this research in three important ways. First, we introduce a novel dataset that allows for a detailed measurement of procedural reforms. In spite of a sustained political science interest in the institutional history of the House of Commons, we still lack a full picture of institutional reforms of the UK parliament. A key obstacle to progress in this area is the unavailability of a machine-readable dataset of the House of Commons' internal rules - the Standing Orders - covering an extended period. In studying procedural change, analysts of the UK parliament tend to rely on Erskine May (2011), a regularly updated commentary on parliamentary conventions and procedures. However, this source does not provide a systematic overview of formal rule changes. Researchers thus find it difficult to pinpoint changes in procedural institutions, let alone trace the evolution of individual mechanisms over time. In this paper, we introduce a new and complete dataset of all amendments to the Standing Orders of the UK House of Commons (HCSOs) between 1811 and 2015. ${ }^{1}$ This dataset presents, to our knowledge, the first comprehensive and systematic overview of the House's procedures that spans nearly the entirety of the nineteenth and twentieth centuries. Based on this novel source, researchers will be able to compare the texts of the HCSOs for any dates between 1811 and 2015, and to trace the evolution of individual rules over time.

Second, we demonstrate how our dataset can be used to construct measures of procedural change. In the spirit of Sieberer, Meißner, et al. (2016), we develop measures of the procedural evolution of the UK House of Commons at the macro, meso, and micro levels. Our macro-level view provides a first glimpse of the way in which the textual length of the rules of procedure evolved between 1811 and 2015, both at the level of simple words or article counts and text additions, deletions, and amendments. Moreover, we show how automatic keyword-based labelling of orders in our data can be used to construct measures of procedural change at the meso level. Based on such measures, our article traces the evolution of rules in the domains of government rights, committee powers, European integration, and devolution. Finally, we show how our data can facilitate systematic manual or automated labelling of the content of changes at the micro-level of individual clauses.

\footnotetext{
${ }^{1}$ We begin in 1811 because a reliable identification of the House of Commons Standing Orders before this year is problematic - see Kemp (1971).
} 
Third, we offer an illustrative application of our data in an exploratory analysis of determinants of procedural change in the UK House of Commons. We use our data to generate a measure of procedural change. We then model the incidence and magnitude of change to test several theoretical expectations drawn from recent research on parliamentary rules as equilibrium behavioural patterns (Sieberer, Müller, and Heller 2011). We find suggestive evidence that disturbances to the partisan environment affect patterns of reform. In particular, changes in party control increase the occurrence of procedural reforms, while disturbances in the level of polarization reduce the extent of reform. This analysis demonstrates our dataset's potential to advance our understanding of the origin and evolution of legislative institutions.

The remainder of this paper proceeds as follows. Section 2 outlines how we have constructed our new dataset of the Standing Orders, and describes its key features. Section 3 shows how our dataset can be used to construct different measure of procedural change at the macro, meso and micro levels. Section 4 presents our empirical application and the results. Section 5 concludes, outlining potential other uses of our dataset.

\section{House of Commons Standing Orders, 1811-2015}

\subsection{The Limits of Existing Sources}

The formal rules governing procedure in the UK House of Commons are to be found in the text of the Standing Orders (henceforth HCSOs). These rules are determined by members of Parliament, and can be amended by a simple majority vote. Any MP can propose amendments, though the Cabinet's control of the parliamentary agenda typically prevents discussion of proposals lacking government support (Russell 2011). ${ }^{2}$ Alternatively, MPs can decide to charge a special rules committee to review and propose changes to the Standing Orders. ${ }^{3}$

\footnotetext{
${ }^{2}$ Though agenda control was much less centralized in the nineteenth century, the Cabinet still had a number of advantages that allowed them to shape the development of the Standing Orders (see Cox 1987, pp. 64-65).

${ }^{3}$ An interesting avenue for research would be to focus on how these different means by which rules are proposed affect their likelihood of being adopted. The suggested changes emanating from a special rules
} 
Official versions of the House's Standing Orders have been published in print since the early nineteenth century, and their scanned PDF versions are now available online through the UK Parliamentary Papers database. ${ }^{4}$ Each of these documents contains the full text of all the procedural rules (Orders) governing business in the House of Commons as they were in force at the time of publication. Although the official editions provide an abundance of textual information, they are a rather awkward source for researchers wishing to systematically study changes in the Commons' formal rules. This is due to three main limitations.

First, official versions of the HCSOs have been published at irregular intervals, rather than every time the rules were changed. Each version thus consolidates into a single text all the procedural changes adopted by the House of Commons in the previous months, and sometimes years. As a result, scholars cannot simply compare successive editions of the HCSOs to identify when and how they have changed. Instead, anyone interested to analyze the rules in force at any point in time, must painstakingly reconstruct how the rules evolved since the last print edition. This is especially difficult for the period before 1902, when the HCSO print editions did not indicate the dates of rule changes. Any analyst of the House's procedural evolution in the nineteenth century is thus faced with a daunting task of trawling though the Hansard sessional records to collect information about when changes were adopted.

Second, reliable machine-readable versions of the HCSOs are not currently available. This hinders systematic comparisons between different versions of the HCSOs, whether at the level of the entire text, its component parts, or when focusing on particular clauses and sub-clauses. Anyone wishing to understand the procedural changes made at a given time must manually compare different versions line by line, as well as consult other sources to identify what modifications were made. Consequently, little use can be made of the widely available tools for automatic document comparison - a drawback that makes the analysis of change in the Commons' rules over time difficult. In particular, it makes aggregate comparisons over longer time periods prohibitively time-consuming.

committee can, for example, generally be expected to be less contentious than proposals put to the floor by the government (see also our discussion in Section 4). Though we recognise that there is an important distinction in these processes, a study of their effect is beyond the scope of our paper.

${ }^{4}$ The database is available at parlipapers.proquest.com. 
Third, current versions of the HCSOs do not allow for effective human (or automated) coding of the nature of changes in procedural rules. Due to frequent re-numbering and reordering of the Standing Orders, there is no straightforward method for analyzing the timelines of specific procedural rules. Between two editions of the HCSOs, the same Standing Order might be re-numbered, moved to a different place in the text, substantively amended, or some combination of all three. Given these obstacles, a researcher attempting to analyze the evolution of rules relating to such important issues as agenda-setting, committee powers, or speech-making faces a very challenging task indeed.

Given such limitations, existing sources pose serious problems for scholars' ability to describe, measure, and explain changes in the formal procedures of the UK House of Commons. Against this backdrop, we offer a new data source which resolves many of these problems. In particular, our data facilitate both human and automated analysis of the entire Standing Orders, groups of orders relating to a particular topic, or a single order containing a specific procedural rule. In the following subsection, we discuss the construction of our dataset.

\section{$2.2 \quad$ A New Dataset}

Our dataset covers the House of Commons Standing Orders between 21st June 1811 and 26th March 2015. ${ }^{5}$ The handling of business in the UK House of Commons has traditionally been governed by two sets of Standing Orders: one relating to private business and another relating to public business. We focus exclusively on the Standing Orders governing public business, i.e. all matters, including legislation, which apply to the general public. We do not consider the Standing Orders relating to private business because the importance of matters applicable to specific individuals and organizations has steadily declined in the House of Commons since the mid nineteenth century. Furthermore, our focus is only on those orders which are permanent, and so we do not cover orders which, from time to time, were adopted as temporary or "sessional". 6

\footnotetext{
${ }^{5}$ The first version of this dataset was developed by Goet (2018). It was subsequently subjected to important reconstruction in light of the research presented in this joint paper, in particular through the introduction of root and current numbers.

${ }^{6}$ Where Orders were resolutions or temporary orders before being made permanent, we only include them from when this change occurs. We take the same approach to those Orders which move from Private Business to Public Business. The only exception to this is a set of Standing Orders relating to the presentation of
} 
We constructed the new dataset of HCSOs in two steps. In the first stage, we started by identifying all dates on which the House adopted any change to its Standing Orders between 1811 and 2015. For the period before 1902, we used dates printed above each Standing Order to indicate when they were passed or last amended. We also checked these against the records of parliamentary debates (Hansard) and proceedings (the House of Commons Journal) to ensure they were correct. For the period after 1902, we used summaries of amendment dates attached to the official printed versions. For both periods, we manually compared the text of each successive edition to its predecessor, to ensure we had captured all the amendment dates. Having established a complete listing of dates on which the HCSOs were amended, we identified the textual changes made on each of these dates and constructed consolidated text versions of the HCSOs after each date of amendment. ${ }^{7}$ Where there were multiple changes between two printed editions, we disentangled them by referring to the original motions and debates which changed the rules. ${ }^{8}$

In the second step, we compared each consolidated version to its successor at the level of sub-article. A sub-article is defined as the smallest unit of separately labeled or numbered text. ${ }^{9}$ We proceeded as follows. The baseline edition of 21 June 1811 was subdivided into sub-articles and each such unit was assigned a "current number" and a "root number". The former identifies the order of sub-articles within the consolidated version. The latter is a unique identifier allocated at birth to each sub-article within our data. Subsequently, a trained human coder analyzed the next available consolidated version of 22 February 1821. Each sub-article in this new edition was assigned a current number to denote its position, and then compared with sub-articles from the previous edition. Each sub-article which could be matched as an exact copy or an amended version of a sub-article in the previous edition

petitions. These were passed in 1842 but not clearly included in the orders for either Public or Private Business until 1849, when they were listed with the former. We include these orders from 1842, to avoid mistaking editorial changes for substantive changes.

${ }^{7}$ ProQuest have provided us with machine-readable versions of the Standing Orders from 1843 to 2004. The abundance of Optical Character Recognition (OCR) errors in these documents, however, meant our work predominantly consisted of manually converting the scanned PDF versions of the originals to plain text format. We have also cross-checked our work with a historical overview provided by the House of Commons Library.

${ }^{8}$ Again using a combination of Hansard and the House of Commons Journal.

${ }^{9}$ Any unit of text which is preceded by e.g. (1), (a), (i), and so on, is considered a sub-article. In some instances, sections of text which do not fall clearly under another sub-article but which are not themselves labelled or numbered are also treated as sub-articles. 
was assigned the same root number as the sub-article in the previous edition; the sub-articles that could not be matched, were assigned a new unique root number. An effort was made to match as many sub-articles as possible to sub-articles in the previous edition, on the basis of both their content and the specific procedure to which they refer. Appendix $\mathrm{C}$ in the on-line supplementary materials provides a detailed overview of our root number matching procedure, as well as a validation exercise using an automated matching method.

This process continued for each subsequent amendment date. Our final data thus consist of a complete collection of all consolidated versions of the HCSOs for each date on which at least one amendment was made. Within each consolidated version, each sub-article is identified by a unique root number which it receives at birth and which it keeps until it is removed in full, and a current number which identifies its position within the edition. The root numbers allow for a detailed tracing of the evolution of individual sub-articles over time. The current numbers make it possible to produce completed, ordered texts of the HCSOs for any date between 1811 and 2015 .

In total, our dataset includes 251 consolidated versions of the HCSOs, comprising a total of 5469680 tokens, 137300 sub-articles, and 1795 unique root numbers. Full versions of the dataset are available in XML, JSON, and csv formats, and will be made freely available for other researchers to use.

\section{Measuring Procedural Change}

Our new dataset makes it possible, for the first time, to systematically map the evolution of the House of Commons' formal procedures from the early nineteenth century to the present day. Recent work on parliamentary rule changes suggests that this can be done at three different levels of analysis (Sieberer, Meißner, et al. 2016). Macro-level measurements of procedural change describe the broad patterns of change in the entire set of rules over time. Meso-level measurements instead describe these patterns for specific subsets of the rules, defined by the particular subject area they address. ${ }^{10}$ Finally, a micro-level approach

\footnotetext{
${ }^{10}$ Sieberer, Meißner, et al. (2016, pp. 78-81) distinguish between two kinds of meso-level analysis. One ("Meso I") defines subsets of rules by their subject area, while another ("Meso II") defines them by their expected effects. We focus on the former approach.
} 
entails tracing the evolution of specific rules over time. These three approaches to measuring procedural change each have distinct advantages and weaknesses, and allow researchers to address very different research questions (Sieberer, Meißner, et al. 2016, pp. 78-82). A key strength of our dataset is that it facilitates all three approaches.

First, the dataset can be used to identify macro-level patterns of change and stability in legislative rules. This is not least because the dataset is machine-readable, allowing us to apply simple automated textual analysis methods. It is also due to the system of root numbers described above, which allows us to identify change at the level of meaningful subunits of the text. In this vein, Figure 1 plots the size of the HCSOs over time, showing the number of words and the number of sub-articles since 1811. Two clear patterns emerge from this. The HCSOs have substantially expanded over time. Yet this has proceeded unevenly, with a long period of gradual change being followed by a quicker expansion from the middle of the twentieth century. Strikingly, the HCSOs have more than doubled in length since the start of the twenty-first century.
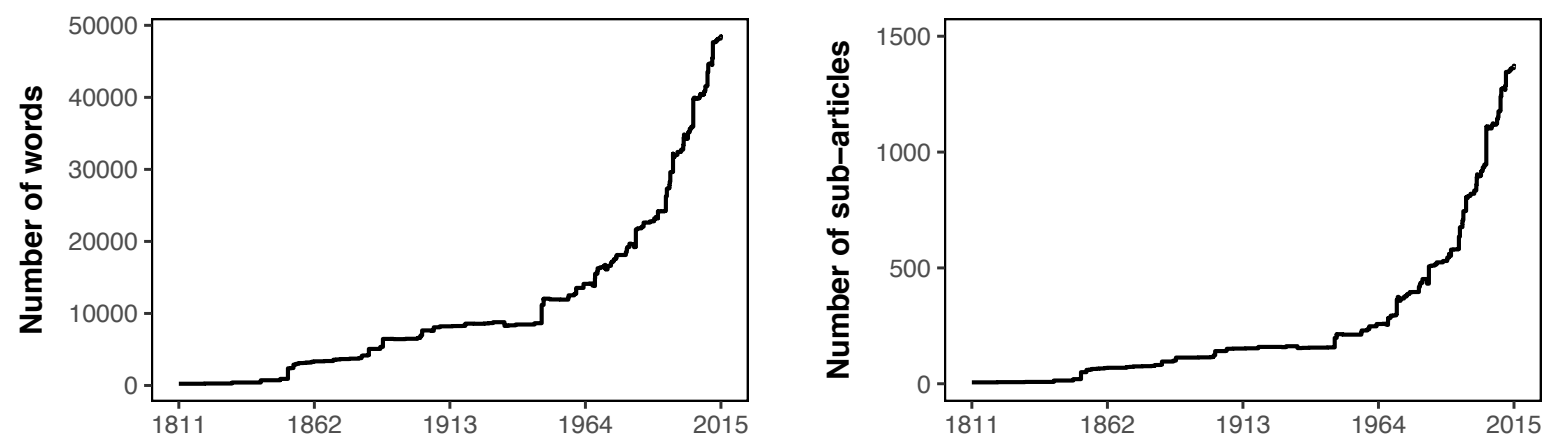

Figure 1: Evolution of Standing Orders, 1811-2015

Where Figure 1 plots changes in the overall size of the Standing Orders, our data can also be used to quantify change at a more fine-grained level. The analyst can, for example, compare the depth of changes made from one version of the Standing Orders to the other in terms of the number of sub-articles added, deleted, or changed. Figure 2 plots such measurements for each parliamentary session between 1811 and 2015, with darker strips indicating more extensive change. Again, we see substantial variation, with periods of procedural stability interspersed with periods of substantial change. The patterns in Figure 2 appear to 
accord with existing knowledge regarding the timing and extent of procedural changes in the Commons. Major instances of reform are clearly visible, such as the centralizing "Balfour reforms" of the 1900s (Dion 1997; Eggers and Spirling 2014; Redlich 1908), the post-war Attlee government's overhaul of the legislative process (Kelso 2009, pp. 34-36), and the extensive "modernization" reforms of the New Labour governments between 1997 and 2010 (Flinders 2002, 2007; Kelso 2009). Our dataset thus allows us to generate substantively meaningful measures of macro-level changes in House of Commons procedure over a period of more than two centuries.

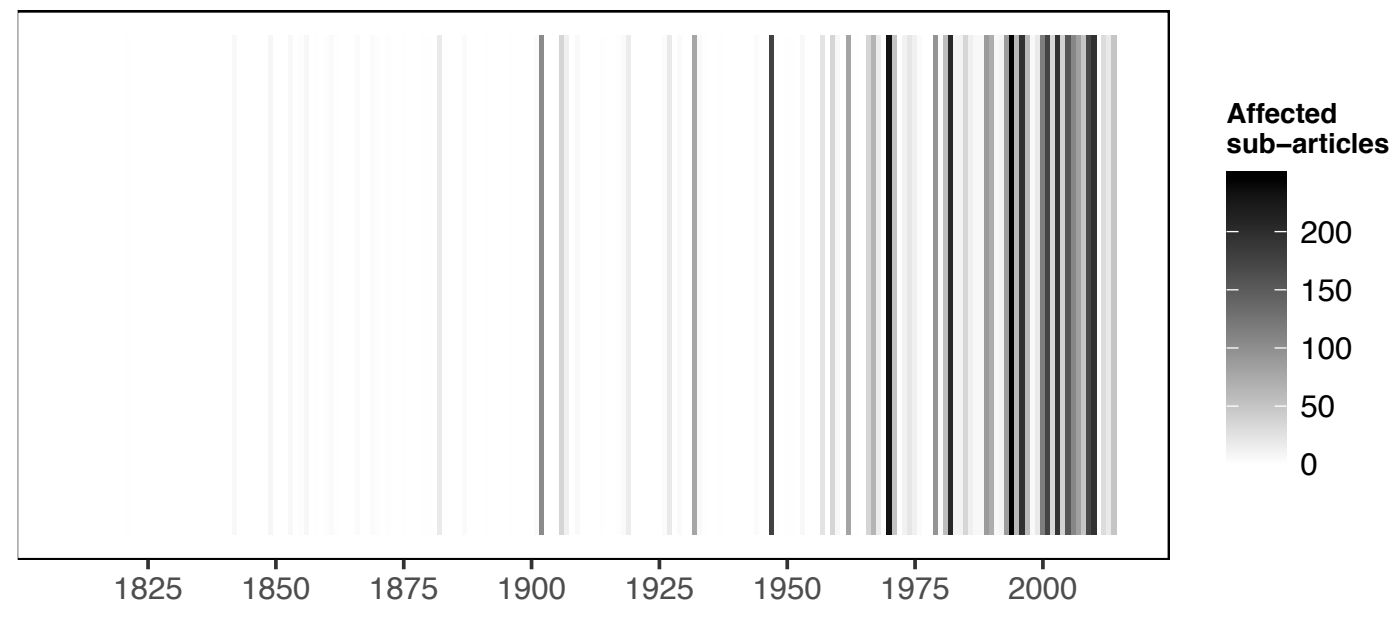

Figure 2: The extent of reform in Standing Orders by session, 1811-2015

Darker strips indicate greater change in the Standing Orders in a given session. This is measured as the total number of sub-articles added, removed, or amended between the start and the end of the session.

Second, a similar approach can be taken to mapping meso-level change in specific kinds of procedures. Figure 3 presents one such application. It shows the evolution of rules in four areas that have received attention in existing work on legislative institutions - the role of the executive (Döring 2001), European integration (Winzen 2017), parliamentary committees (Fleming 2019), and rules specific to one of the UK's constituent nations (i.e. devolution, e.g. Gover and Kenny 2018). We categorize sub-articles on the basis of keyword searches for relevant words or terms, and then plot the changing number of the sub-articles 
in each category. ${ }^{11}$
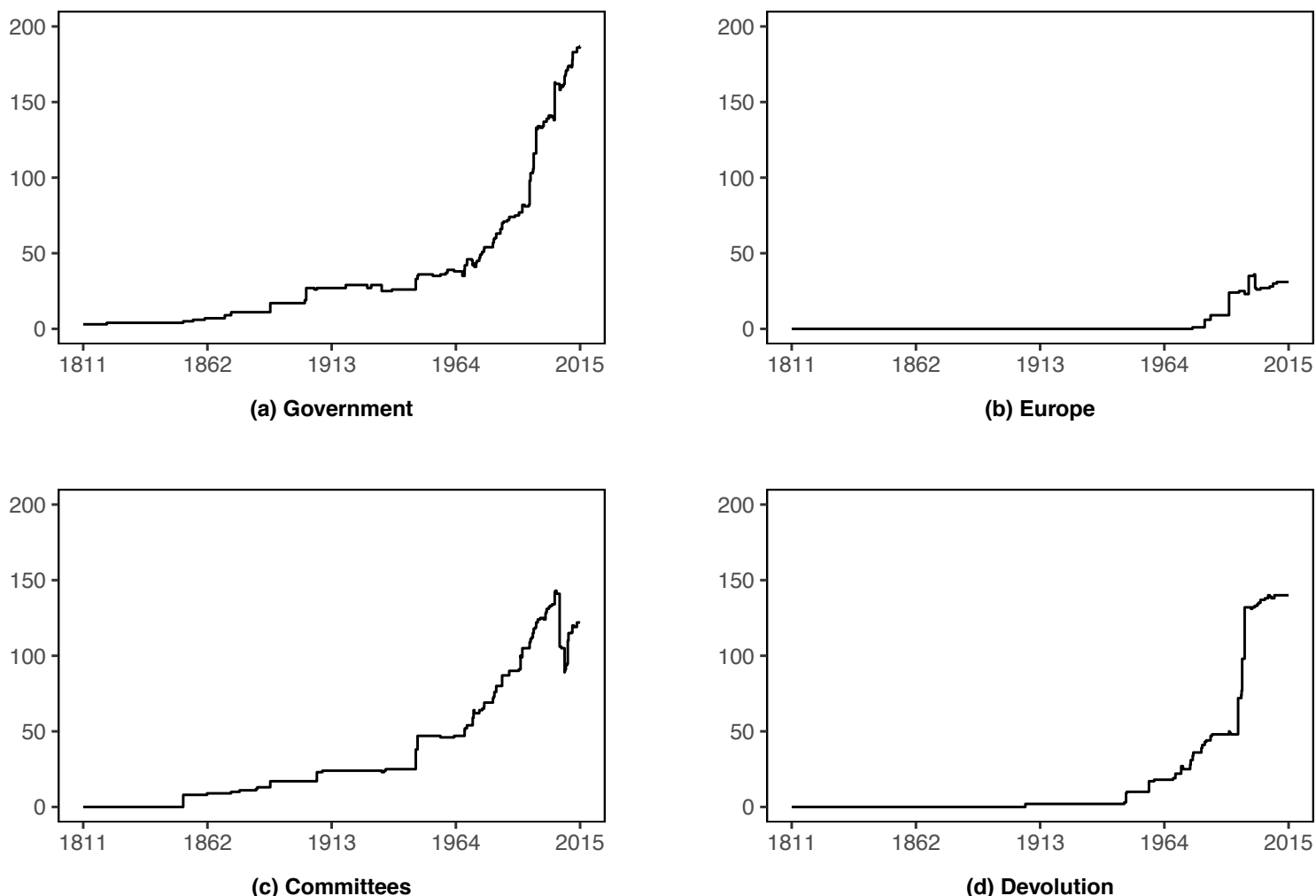

Figure 3: Evolution of procedural topics, 1811-2015

Shows number of sub-articles containing strings relating to four topics - the government ('crown', 'minister', 'government', or 'secretary of state'), Europe ('europe'), committees ('standing committee', 'public bill committee', or 'select committee'), and devolution ('scotland', 'scottish', 'wales', 'welsh', 'england', 'english', 'ireland', or 'irish').

Figure 3 shows a number of interesting patterns. Comparing panel (a) to the others demonstrates that while the role of the executive has been more extensively regulated over time, it has always had a comparatively prominent place in the HCSOs. ${ }^{12}$ By contrast,

\footnotetext{
${ }^{11}$ For a full list of the keywords used, see below Figure 3. This is obviously a very simple approach. It relies on the assumption that the importance of rules in a given area is reflected in the length of those rules. It further depends on us having correctly identified the relevant search terms for each topic. One might instead manually categorize each sub-article based on its content - this approach is beyond the scope of this paper, but also something our dataset makes possible for the first time. We note that plots of the evolution of the length of sub-articles in these dimensions (measured as the number of words) look very similar.

${ }^{12}$ We note, however, that the number of sub-articles relating to a particular topic is only a proxy for the regulatory density of rules. A topic might simply occur frequently where a similar rule is repeated several
} 
panel (b) suggests that European integration has received relatively little prominence in the House's procedures. For obvious reasons, Europe is not mentioned in the HCSOs until the 1970s, but even since, the topic never appears in more than 50 sub-articles. Panel (c) shows that committees became increasingly prominent in the House's rules from the later twentieth century. Despite conventional wisdom suggesting committees play a comparatively minor role in the work of the UK parliament (e.g. Mattson and K. W. Strøm 1995), Figure 3 suggests that the Commons nonetheless devoted over 100 sub-articles to regulating their role at the turn of the twenty-first century. The last panel (d) also presents an interesting pattern. Country-specific procedures in the Commons have received relatively little scholarly attention (though see Gover and Kenny 2018). Yet Figure 3 suggests substantial over-time variation in such procedures. There were no references at all to specific countries until the twentieth century, but then a gradual increase in such references from the middle of the century, and a sharp increase in the last twenty years. This all suggests that generating mesolevel measures of procedural change from our data has the capacity to illuminate important variation in the prominence of different topics in the Commons' formal rules.

Finally, our dataset facilitates micro-level analysis of procedural change, allowing researchers to make very fine-grained comparisons of specific rules over time. We illustrate this by discussing the evolution of an important rule granting the government special prerogatives over proposals for public spending. This sub-article was one of only six in the initial Standing Orders of June 1811, and is still present over two centuries later as Standing Order 48. It has being repeatedly amended and re-numbered in that time, but our system of root numbers enables us to trace it across successive versions of the Standing Orders, and to identify exactly how it has changed. Figure 4 shows how the sub-article has appeared after each amendment, highlighting new text in bold.

This Order sets out the privileged position of the government in making proposals which involve expenditure. It grants the UK government substantial restrictive agenda-setting powers (Döring 1995, pp. 232-233). Figure 4 nicely demonstrates a combination of both continuity and change. On the one hand, this provision has evolved substantially, as its times in the HCSOs, but for only slightly different circumstances. This caveat applies to the length-based measures used in Figure 1 and Figure 3. We thank an anonymous reviewer for bringing this issue to our attention. 


\begin{tabular}{|c|c|c|c|c|}
\hline 21 June 1811 & 25 June 1852 & 20 March 1866 & 14 December $1966^{a}$ & 8 March 1971 \\
\hline $\begin{array}{l}\text { That this House } \\
\text { will receive no Pe- } \\
\text { tition for any Sum } \\
\text { of Money, relating } \\
\text { to Public Service, } \\
\text { but what is recom- } \\
\text { mended from The } \\
\text { Crown. }\end{array}$ & $\begin{array}{l}\text { That this House } \\
\text { will receive no Pe- } \\
\text { tition for any Sum } \\
\text { of Money, relat- } \\
\text { ing to Public Ser- } \\
\text { vice, or proceed } \\
\text { upon any Mo- } \\
\text { tion for grant- } \\
\text { ing any Money, } \\
\text { but what is recom- } \\
\text { mended from The } \\
\text { Crown. }\end{array}$ & $\begin{array}{l}\text { That this House } \\
\text { will receive no Pe- } \\
\text { tition for any Sum } \\
\text { relating to Public } \\
\text { Service, or proceed } \\
\text { upon any Motion } \\
\text { for a Grant or } \\
\text { Charge upon the } \\
\text { Public Revenue, } \\
\text { whether payable } \\
\text { out of the Con- } \\
\text { solidated Fund } \\
\text { or out of Monies } \\
\text { to be provided } \\
\text { by Parliament, } \\
\text { unless recom- } \\
\text { mended from The } \\
\text { Crown. }\end{array}$ & $\begin{array}{l}\text { This house will } \\
\text { receive no pe- } \\
\text { tition for any } \\
\text { sum relating to } \\
\text { public service } \\
\text { or proceed upon } \\
\text { any motion for a } \\
\text { grant or charge } \\
\text { upon the public } \\
\text { revenue, whether } \\
\text { payable out of the } \\
\text { Consolidated Fund } \\
\text { or out of money } \\
\text { to be provided } \\
\text { by Parliament or } \\
\text { for releasing or } \\
\text { compounding } \\
\text { any sum of } \\
\text { money owing to } \\
\text { the Crown, unless } \\
\text { recommended from } \\
\text { the Crown. }\end{array}$ & $\begin{array}{l}\text { This house will } \\
\text { receive no pe- } \\
\text { tition for any } \\
\text { sum relating to } \\
\text { public service } \\
\text { or proceed upon } \\
\text { any motion for a } \\
\text { grant or charge } \\
\text { upon the public } \\
\text { revenue, whether } \\
\text { payable out of the } \\
\text { Consolidated Fund } \\
\text { or the National } \\
\text { Loans Fund or } \\
\text { out of money to } \\
\text { be provided by } \\
\text { Parliament or for } \\
\text { releasing or com- } \\
\text { pounding any sum } \\
\text { of money owing to } \\
\text { the Crown, unless } \\
\text { recommended from } \\
\text { the Crown. }\end{array}$ \\
\hline
\end{tabular}

Figure 4: Tracing the "Life" of an Article (Public Money)

${ }^{a}$ The initial "That" was removed, and "monies" replaced with "money", in 1902.

scope has expanded to cover an increasingly complex range of types of public spending. These changes had potentially important consequences — for example, the 1866 change was introduced with the explicit intention of limiting attempts by ordinary MPs to introduce bills committing Parliament to future expenditure (HC Deb 20 March 1866, cc. 591-603). On the other hand, none of these changes alter the basic intention of the Order - to grant the government control over proposals involving public expenditure.

We have focused on a qualitative analysis of just one important rule here, but our data mean the same approach could easily be applied to any sub-article, or groups of sub-articles, in the Standing Orders since 1811. Furthermore, future research may conduct such microlevel analysis using other approaches, for example, employing quantitative text similarity measures or utilizing text meta data such as parts-of-speech tagging (see e.g. Wilkerson, Smith, and Stramp 2015). ${ }^{13}$

\footnotetext{
${ }^{13}$ We thank an anonymous reviewer for this suggestion.
} 


\section{Explaining Rules Change: An Exploratory Analysis}

Parliamentary procedures can be stable, remaining unchanged over many years. They can also be subject to dramatic change, with important consequences for the outcomes of legislative politics. What explains this variation in procedural stability? In this section, we show how one can use our data to test expectations regarding determinants of procedural change drawn from recent literature. Ours is an illustrative analysis and, while it shows some interesting patterns, we leave more systematic tests for future research.

\subsection{Theoretical expectations}

There are many partisan and non-partisan theories of procedural change in democratic legislatures (Binder 1996; Cox and McCubbins 2005; Diermeier 1995; Diermeier and Myerson 1999; Diermeier and Vlaicu 2011; Gilligan and Krehbiel 1987; Schickler 2000). Most theories have been designed to generate expectations regarding the directionality of change in legislative procedures. Here we focus on a more basic set of theoretical expectations regarding the incidence and magnitude of procedural change. In rational choice theory, institutions are typically viewed as equilibrium behavioral patterns in an underlying game (Calvert 1995). They persist as long as the parameters of this underlying game remain unchanged. Once the game's parameters change, opportunities for a new equilibrium of behavior emerge. Drawing on these insights, Sieberer, Müller and colleagues have recently proposed a model explaining formal rule change in parliamentary democracies (Sieberer, Meißner, et al. 2016; Sieberer and Müller 2015; Sieberer, Müller, and Heller 2011). The core of their argument is that procedural reforms should become more likely, and be more extensive, when significant disturbances occur in the environment within which legislative actors operate.

We use our dataset to put this theoretical claim to an exploratory empirical test. In

particular, we test four expectations about how significant disturbances in the nature of the partisan environment may affect the incidence and magnitude of parliamentary reforms. First, we test for the effect of changes in the partisan composition of governments. Legislative rules may make particular types of policy outcomes more or less likely. If rules 
reflect partisan interests, and rule changes are driven by partisan goals, changes of governing parties should destabilize rules (e.g. Sieberer, Müller, and Heller 2011). Second, we examine the effect of changes in the majority or minority status of cabinets. Minority governments cannot achieve their policy objectives purely by relying on legislative strength. Instead, various restrictive procedures can enhance their ability to control the agenda. Majority governments, by contrast, have less need of such procedures - control of a legislative majority may substitute for them. To the extent to which the institutional preferences of majority and minority cabinets differ, changes from one to the other, and vice versa, should be related to institutional change (e.g. K. Strøm 1990). Third, we test for the impact of changes in the heterogeneity of governing parties. Scholars expect coalition and single-party governments to have different institutional preferences (L. W. Martin and Vanberg 2011; Zubek 2015a). In particular, ideological tensions inside multi-party governments are likely to generate incentives for empowering backbench legislators to scrutinize the executive. By contrast, single-party governments may wish to restrict such procedures, lest they be used by opposition MPs as well as those from governing parties. If single-party and multi-party governments have different institutional preferences, shifts from one to the other, and vice versa, should destabilize institutions. Finally, we expect changes in the partisan polarization of the legislature - i.e. the degree to which ideological preferences are clustered within parties - to undermine the stability of regularized patterns of parliamentary behaviour (Diermeier and Vlaicu 2011; Goet 2019b). ${ }^{14}$

\subsection{Data and Model}

To test our expectations, we first construct a measure of the magnitude of procedural reforms undertaken in each parliamentary session between 1811 and $2015 .{ }^{15}$ Our dependent variable is the total number of sub-articles added, removed, or changed during a session. (See Figure 2 above). Our unit of analysis is the parliamentary session, giving us a total

\footnotetext{
${ }^{14}$ Our concept of polarization refers to the degree of "partyness" of members, deriving from Krehbiel's "weak parties" model (Krehbiel 1991). Parties are groups of individuals that share similar ideological views. The House is "polarized" when preferences are concentrated within parties.

${ }^{15} \mathrm{~A}$ parliamentary session is the (typically) one-year period between the state opening of parliament and its prorogation.
} 
of 233 observations, spanning 205 years between 1811 and 2015. Table 1 summarizes our independent variables. All main predictors are lagged by one session, and represent a change prior to the session to ensure that the temporal order of events is sequenced correctly ${ }^{16,17}$. The first five variables are coded 1 if change occurred in the previous session or in the gap between the previous and the current session. Otherwise, they are coded 0. Sources of data for these variables are described in the on-line supplementary material.

To capture change in partisan polarization, we use novel data from Goet (2019a) (see also Peterson and Spirling 2018). This approach trains a machine classifier on labelled speech data and subsequently takes the accuracy of predicting the party label of held-out samples of speeches as a measure of polarization. The measure therefore captures how well we can predict the party membership of MPs based on their language use. This speechbased measure of "partyness" is taken to be a good indicator of separation of MPs into distinct ideological camps, i.e. of how closely they identify with their respective parties (for a validation of this approach, see Goet 2019a). In our study, the change in polarization associated with a session $t$ is defined as polarization $_{t-2}-$ polarization $_{t-1}$, thus capturing the degree to which "partyness" increases or decreases from one session to the next.

We use three controls: (i) the session length to account for varying levels of exposure time $^{18}$, (ii) the number of sub-articles in place at the start of the session (logged), and (iii) the time trend operationalized as the number of years that lapsed since 1811. This last

\footnotetext{
${ }^{16}$ Our robustness checks show that our model with the selected lagging structure obtains a higher fit as measured by the AIC than alternatives with one and two additional lags. The AIC for the full model reported in this article is 1026.49 (column 7, Table A1), compared to 1030.44 ( 1 additional lag), and 1042.65 (2 additional lags). The results for the models with additional lags are included in the replication materials.

${ }^{17}$ We note that in spite of our lagging structure, there is potential endogeneity in the relationship between rules and some of our independent variables. If specific rules lead to certain political outcomes, parties have an interest in shaping these rules to favour their interests (e.g. Cox 2006). This may in turn lead to rules affecting, for example, what kind of government forms after the next election. With our modelling strategy, we are unable to account for this endogeneity and the results should be read with this caveat in mind.

${ }^{18}$ We cannot assume that each observation in our dataset is at risk of an event occurring for the same amount of time. This is because the observations in our dataset have varying exposure times, i.e. the length of each parliamentary session varies in our dataset. Reforms may be more likely when there is more time to implement a change (and vice versa). We can incorporate different exposure times into our models in two ways (Long and Freese 2014). First, the effect of different exposure times can be incorporated into the model as the log of exposure times with the coefficient constrained to 1 . This method assumes that the effect of exposure time is constant over time. Second, if we want to relax this last assumption, we could estimate a coefficient for the log of exposure time instead of constraining it to 1 . Since we do not have any a priori expectations about how the hazard of reforms varies within a session, we opt for the latter method and introduce a predictor for the log of the length of the session measured in days.
} 
variable is included as both a log term and a squared log term.

Table 1: Summary Statistics for Independent Variables and Controls

\begin{tabular}{lrr}
\hline & Mean & S.D. \\
\hline Main predictors & & \\
Party control change & 0.16 & 0.37 \\
Majority to minority & 0.06 & 0.23 \\
Minority to majority & 0.06 & 0.23 \\
Single-party to coalition & 0.03 & 0.17 \\
Coalition to single party & 0.03 & 0.16 \\
Polarization change & 0.00 & 0.04 \\
Controls & & \\
Number of session days & 108.02 & 57.07 \\
Number of sub-articles at $\mathrm{t}_{0}$ & 217.37 & 283.52 \\
\hline
\end{tabular}

To model the effect of our predictors on the incidence and magnitude of procedural change, we use a hurdle model specification. We employ the hurdle model for both theoretical and statistical reasons. In this specification, the binary outcome of whether the count equals zero or is greater than zero is governed by a binomial probability model. If the outcome is positive (i.e. the "hurdle" is crossed), a truncated-at-zero count data model governs the conditional distribution of the positives (cf. Mullahy 1986). This model specification is particularly suited to sequential decision-making processes, where the positive cases and the zeros derive from different data-generating processes. From a theoretical perspective, we believe that this model corresponds closely to the process of parliamentary reform. Rules are known to be "sticky" and difficult to change (e.g. Binder 1997; Shepsle 1986). Once sufficient support is secured to amend or implement a rule, in a second stage further consensus will have to be built on the extent of these reforms. Clearing the first "hurdle" of implementing a procedural reform, and subsequently deciding on the scope of such reform, therefore maps well onto the assumptions of the hurdle model.

Second, in statistical terms, the hurdle model allows us to deal with over-dispersion of our dependent variable ${ }^{19}$, and the inflation of zeros. Specifically, we employ the negative binomial model for the count component, and the binomial model with logit link for the hurdle part of the model. The negative binomial model is preferable as it allows us to model

\footnotetext{
${ }^{19}$ I.e. $\mu<\sigma^{2}$; here: $\mu=3.24$ and $\sigma^{2}=192.02$.
} 
data with a much wider range of variability (e.g. Zeileis, Kleiber, and Jackman 2008). In all models, we cluster standard errors at the parliament level in order to account for unexplained variation relating to the specific parliamentary term in which the session is embedded. ${ }^{20}$

\subsection{Results}

Figure 5 plots the results from our full hurdle model, with all controls and trend predictors (Model 7 in Appendix A). The left panel presents coefficients from the binomial component of the hurdle model, while the right panel shows coefficients from the count model. In both panels, we also report the associated $95 \%$ confidence intervals. Other model specifications, including bivariate models and models without controls, can be found in Appendix A. Overall, these results provide some tentative evidence that the incidence, and in particular the magnitude of procedural change, may be related to disturbances in the partisan environment.

The binomial results show that changes in party control increase the likelihood of institutional change. The odds of a reform increase by 263.57 percent in sessions that were preceded by a change in party control, compared to sessions in which the incumbent government continued. This effect is statistically significant at a 90 percent confidence level $(\mathrm{p}=0.081)$. This finding corresponds with insights from more qualitative work on the UK House of Commons that suggest that government parties and their priorities are key to understanding parliamentary reforms in the House (e.g. Russell 2011). Our other predictors, however, have little explanatory power when it comes to the likelihood of reform. The p-values for these other coefficients do not reach the conventional level of statistical significance.

We obtain more promising results from the count estimation, which models the depth of reform. As we are dealing with a hurdle specification, the results of the count component of the model show the effect of variables given that a reform has taken place. First and foremost, changes in partisan polarization are found to affect the depth of procedural change. Specifically, increases in the level of polarization decrease the depth of reforms. The substantive effect of this variable is large: the predicted count of reforms at two standard deviations below the mean level of polarization change is about six compared to one at two

\footnotetext{
${ }^{20}$ The hurdle model is estimated as a single model, and hence the hurdle and count component include the same predictors.
} 


\section{Incidence of reform (binomial)}

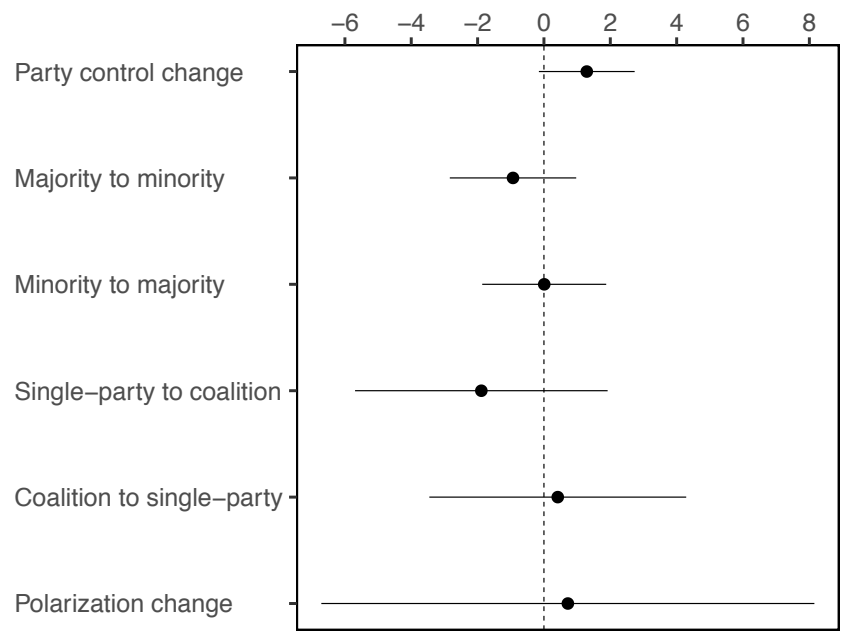

Depth of reform (neg. bin.)

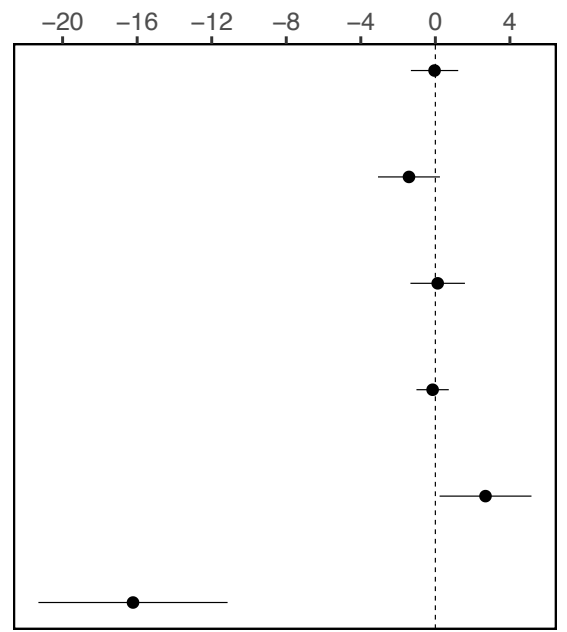

Figure 5: Hurdle Model Estimates

Coefficient estimates and 95 percent confidence intervals, from model (7) in Table A1 in Appendix A.1.

standard deviations above the mean, holding all other variables constant and given that a procedural change has occurred..$^{21}$

Beyond polarization, changes from majority to minority governments have a negative effect on the depth of reform. The predicted number of sub-articles deleted, added, or changed is two if the cabinet status loses a majority status in the previous session, compared to seven in cases where such a change of majority status does not occur, holding all else constant. Furthermore, a change from coalition to single-party government (although not vice versa) increases the depth of reforms. Such alterations of government type in the previous session increase the predicted number of procedural changes from two to nineteen reforms. At the same time, we do not find evidence for the effect of changes from minority to majority status. Similarly, changes from single-party to coalition government do not exercise a statistically significant effect. Neither is change in party control important for the depth of procedural change.

\footnotetext{
${ }^{21}$ For these and all other reported predicted counts, all other predictors are held at the mean except for factor variables (majority to minority, and vice versa), which are held at their mode. The reported predicted counts are defined as the expectation from the complete hurdle model, which is equivalent to the probability of crossing the hurdle multiplied by the truncated expectation of the count part.
} 
We perform some robustness tests on our results, jackknifing for both individual sessions and for entire parliaments (see Appendix A.2 for details and a visual presentation of our robustness analyses). Our analyses show that the effect of polarization change maintains statistical significance at the highest levels regardless of which session or parliament is excluded (see Figure A4). Meanwhile, the p-value for the effect of changes in party control falls just short of statistical significance at the 90 percent confidence level once one parliament and one session are omitted from the analysis (see Figure A1). ${ }^{22}$ The effects of changes from majority to minority government status and of coalition to single-party government do not hold up to closer scrutiny: both effects are very sensitive to both parliament- and session-jackknifing (see Figures A2 and A3).

Overall, our empirical analysis yields some support for the expectation that procedural change in the UK parliament is, at least in part, related to disturbances in the partisan environment. In particular, we find robust evidence to suggest that increases in the level of polarization reduce the depth of reform. This finding resonates with earlier studies of the Commons, and in particular with a recent study by Goet (2019b) of the same period (1811-2015), which shows that changes in the House's debating rules are less likely when interparty polarization is high. Like Goet (2019b) we therefore find some evidence to suggest that polarization is an important driver of procedural reforms, although our results indicate that greater ideological divergences between parties affect the depth rather than the incidence of procedural reforms.

Beyond polarization, we fail to find robust evidence for an effect of our other predictors on the probability and depth of reforms. This is likely a consequence of limitations of our data, in several ways. First, our dependent variable - which counts the number of reforms in a given session - inevitably reduces different kinds of reforms to the same data-generating process. However, we may expect that different kinds of procedural changes occur through different processes. Moreover, government-proposed changes such as the closure rules of 1882 and 1887 (e.g. Koß 2015) are likely driven by different factors than smaller, efficiency-

\footnotetext{
${ }^{22}$ The $\mathrm{p}$-value rises to $p=0.12$ for one case in the parliament jackknifing, and to the same $\mathrm{p}$-value in the session jackknifing. This effect relates to a session in 1841 that was preceded by a change of government, but which was not accompanied by a large change in the standing orders. This however was at a time when only eight SOs for public business were in place, reducing the scope for such changes.
} 
focused changes proposed by a rules reform committee. Second, our dummy variables for changes in majority status, government type, and party control change may not be granular enough to tease out some of the effects that we have hypothesised. Finally, given that our analysis focuses on institutional change over a prolonged time frame, we inevitably are unable to account for many important determinants, including political leadership and extraneous events. In spite of these limitations, our study is a first important step in the study of the determinants of institutional change in the UK House of Commons over a prolonged period of time.

\section{Conclusion}

In this paper, we have introduced a new, machine-readable dataset of all reforms of the Standing Orders of the UK House of Commons from 1811 to 2015. There has been a large scholarly interest in the evolution of legislative institutions in general, and the UK parliament in particular. Despite this, limitations of existing data sources make it very challenging to systematically describe and measure changes in parliamentary rules over time. Our dataset addresses this problem, allowing researchers to identify all the formal parliamentary rules in place on any given day since 1811, and to trace how specific rules have evolved over that period. It thus represents a significant contribution to this field.

We have demonstrated the potential of our dataset in a number of ways. First, we have shown how it can be used to describe and measure procedural change at macro, meso, and micro levels. Using simple measures, we were able to trace the evolution of the rules as a whole, broad categories of rules, or specific individual rules, over more than two centuries. Second, we applied one macro-level measure in an exploratory analysis of the drivers of procedural reform. Testing expectations drawn from existing work on institutional change, we found that the procedural equilibrium in the UK House of Commons between 1811 and 2015 was upset by changes in party control of government, and by changes in polarization.

Of these findings, those relating to changes in polarization are more robust than those relating to changes in party control. Our dataset has thus allowed us to contribute to the growing literature on the origin and evolution of legislative institutions. In particular, we 
offer new suggestive evidence to support the idea that parliaments' rules are influenced by their partisan environment (Sieberer, Meißner, et al. 2016; Sieberer and Müller 2015; Sieberer, Müller, and Heller 2011).

Beyond the measures and analysis presented here, we believe our dataset has the potential to greatly advance the study of institutional change in the UK House of Commons, inspiring a range of further applications. Scholars might use this data to trace and explain the evolving role of the Speaker, the power of committees, or the legislative process. The dataset might also be fruitfully connected to data on legislative debate or legislative votes, to address a wider range of questions. Comparing our data to speech data, researchers might ask whether procedural rules tend to reflect the priorities or positions of a particular party. Linking our procedural data to information on voting patterns, scholars might ask whether institutions adopted by consensus are more durable. The work set out here may also have implications for the wider study of legislative institutions. We have described a clear process for collecting, formatting, and organizing this kind of data, which might provide a template for those who wish to produce comparable datasets for other legislatures. This in turn could facilitate further advances in the comparative study of how legislative institutions evolve. We leave these various possibilities for future work. 


\section{References}

Binder, Sarah A. (1996). "The Partisan Basis of Procedural Choice: Allocating Parliamentary Rights in the House, 1789-1990". American Political Science Review 90.1, pp. 8-20.

- (1997). Minority Rights and Majority Rule: Partisanship and the Development of Congress. Cambridge: Cambridge University Press.

- (2006). "Parties and Institutional Choice Revisited". Legislative Studies Quarterly 31.4, pp. 513-32.

Calvert, Randall L. (1995). "Rational Actors, Equilibrium, and Social Institutions". Explaining Social Institutions. Ed. by Jack Knight and Itai Sened. Ann Arbor, MI: University of Michigan Press, pp. 5793.

Cox, Gary W. (1987). The Efficient Secret: The Cabinet and the Development of Political Parties. Cambridge: Cambridge University Press.

- (2006). "The Organisation of Democratic Legislatures". The Oxford Handbook of Political Economy. Ed. by Barry Weingast and Donald Wittman. Oxford: Oxford University Press, pp. 141-161.

Cox, Gary W. and Mathew D. McCubbins (2005). Setting the Agenda: Responsible Party Government in the U.S. House of Representatives. New York: Cambridge University Press.

Diermeier, Daniel (1995). "Commitment, Deference, and Legislative Institutions". American Political Science Review 90.2, pp. 344-355.

Diermeier, Daniel and Roger B. Myerson (1999). "Bicameralism and Its Consequences for the Internal Organization of Legislatures". American Economic Review 89.5, pp. 1182-96.

Diermeier, Daniel and Razvan Vlaicu (2011). "Parties, Coalitions, and the Internal Organization of Legislatures". American Political Science Review 105 (2), pp. 359-380.

Dion, Douglas (1997). Turning the Legislative Thumbscrew: Minority Rights and Procedural Change in Legislative Politics. Ann Arbor: The University of Michigan Press.

Döring, Herbert (1995). "Time as a Scarce Resource: Government Control of the Agenda". Parliaments and Majority Rule in Western Europe. Ed. by Herbert Döring. New York: St. Martin's Press, pp. 223-246.

- (2001). "Parliamentary Agenda Control and Legislative Outcomes in Western Europe". Legislative Studies Quarterly 26.1, pp. 145-165. URL: http://www.jstor.org/stable/440407.

Eggers, Andrew C. and Arthur Spirling (2014). "Ministerial Responsiveness in Westminster Systems: Institutional Choices and House of Commons Debate, 1832-1915". American Journal of Political Science 58 (4), pp. 873-887.

- (2018). "The Shadow Cabinet in Westminster Systems: Modeling Opposition Agenda Setting in the House of Commons, 1832-1915". British Journal of Political Science 48 (2), pp. 343-367.

Fleming, Thomas G. (2019). "Partisan dealignment and committee power in five Westminster parliaments". European Journal of Political Research 58 (2), pp. 536-556. 
Flinders, Matthew (2002). "Shifting the Balance? Parliament, the Executive and the British Constitution". Political Studies 50 (1), pp. 23-42.

- (2007). "Analysing Reform: The House of Commons, 2001-5". Political Studies 55 (1), pp. 174-200.

Fraser, Peter (1960). "The Growth of Ministerial Control in the Nineteenth-Century House of Commons". The English Historical Review 75 (296), pp. 444-463.

Gilligan, Thomas W. and Keith Krehbiel (1987). "Collective Decision-Making and Standing Committees: An Informational Rationale for Restrictive Amendment Procedures". Journal of Law, Economics and Organization 3, pp. 287-335.

Goet, Niels D. (2018). "The Politics of Procedural Choice: Regulating Legislative Debate in the UK House of Commons, 1811-2015". PhD thesis. University of Oxford.

- (2019a). "Measuring Polarization with Text Analysis: Evidence from the UK House of Commons, 1811-2015". Political Analysis FirstView, pp. 1-22.

- (2019b). "The Politics of Procedural Choice: Regulating Legislative Debate in the UK House of Commons, 1811-2015". British Journal of Political Science (conditionally accepted).

Gover, Daniel and Michael Kenny (2018). "Answering the West Lothian Question? A Critical Assessment of 'English Votes for English Laws' in the UK Parliament". Parliamentary Affairs. 71 (4), pp. 760-782.

Jogerst, Michael (1993). Reform in the House of Commons: The Select Committee System. Lexington: The University Press of Kentucky.

Kelso, Alexandra (2009). Parliamentary Reform at Westminster. Manchester: Manchester University Press. Kemp, Betty (1971). "Votes and Standing Orders of the House of Commons: The Beginning". House of Commons Library Document No. 8. London: Her Majesty's Stationery Office.

Koß, Michael (2015). "The Origins of Parliamentary Agenda Control: A Comparative Process Tracing Analysis". West European Politics 5 (38), pp. 1062-1085.

Krehbiel, Keith (1991). Information and Legislative Organization. Ann Arbor: University of Michigan Press.

Long, Scott J. and Jeremy Freese (2014). Regression Models for Categorical Dependent Variables Using Stata. College Station: Stata Press.

Martin, Lanny W. and Georg Vanberg (2011). Parliaments and Coalitions: The Role of Legislative Institutions in Multiparty Governance. Oxford: Oxford University Press.

Mattson, Ingvar and Kaare W. Strøm (1995). "Parliamentary Committees". Parliaments and Majority Rule in Western Europe. Ed. by Herbert Döring. New York: St. Martin's Press, pp. 249-307.

May, Erskine (2011). Erskine Mayś treatise on the law, privileges, proceedings and usage of Parliament. 24th. London: LexisNexis.

Mullahy, John (1986). "Specification and testing of some modified count data models". Journal of Econometrics 33.3, pp. 341-365.

Peterson, Andrew and Arthur Spirling (2018). "Classification Accuracy as a Substantive Quantity of Interest: Measuring Polarization in Westminster Systems". Political Analysis 26 (1). 
Rasch, Bjorn Erik, Shane Martin, and Jose Antonio Cheibub, eds. (2015). Parliaments and Government Formation: Unpacking Investiture Rules. Oxford: Oxford University Press.

Redlich, Josef (1908). The Procedure of the House of Commons: A Study of Its History and Present Form. Vol. 1. Translated from German by A. Ernest Steinthal. London: Archibald Constable \& Co. Ltd.

Russell, Meg (2011). "Never Allow a Crisis Go To Waste': The Wright Committee Reforms to Strengthen the House of Commons". Parliamentary Affairs 64 (4), pp. 612-633.

Schickler, Eric (2000). "Institutional Change in the House of Representatives, 1867-1998: A Test of Partisan and Ideological Power Balance Models". The American Political Science Review 2 (94), pp. 269-288.

- (2001). Disjointed Pluralism: Institutional Innovation and the Development of the US Congress. Princeton: Princeton University Press.

Shepsle, Kenneth A. (1986). "institutional Equilibrium and Equilibrium Institutions". Political Science: The Science of Politics. Ed. by Herbert F. Weisberg. New York: Agathon Press, Inc., pp. 51-81.

Sieberer, Ulrich, Peter Meißner, et al. (2016). "Mapping and Explaining Parliamentary Rule Changes in Europe: A Research Program". Legislative Studies Quarterly 41 (1), pp. 61-88.

Sieberer, Ulrich and Wolfgang C. Müller (2015). "Explaining Reforms of Parliamentary Minority Rights: A Theoretical Framework with Case Study Application". West European Politics 38.5, pp. 997-1019.

Sieberer, Ulrich, Wolfgang C. Müller, and Maiko Isabelle Heller (2011). "Reforming the Rules of the Parliamentary Game: Measuring and Explaining Changes in Parliamentary Rules in Austria, Germany, and Switzerland, 1945-2010". West European Politics 34 (5), pp. 948-975.

Sin, Gisela (2015). Seperation of Powers and Legislative Organization: The President, the Senate, and Political Parties in the Making of House Rules. Cambridge University Press: Cambridge.

Spirling, Arthur (2014). "British Political Development: A Research Agenda". Legislative Studies Quarterly 39 (4), pp. 435-437.

Strøm, Kaare (1990). "A Behavioral Theory of Competitive Political Parties". American Journal of Political Science 34 (2), pp. 565-598.

Wilkerson, John, David Smith, and Nicholas Stramp (2015). "Tracing the flow of policy ideas in legislatures: A text reuse approach". American Journal of Political Science 59 (4), pp. 943-956.

Winzen, Thomas (2017). Constitutional Preferences and Parliamentary Reform: Explaining National Parliaments' Adaptation to European Integration. Oxford: Oxford University Press.

Zeileis, Achim, Christian Kleiber, and Simon Jackman (2008). "Regression Models for Count Data in R". Journal of Statistical Software 27 (8), pp. 1-25.

Zubek, Radoslaw (2015a). "Coalition Government and Committee Power". West European Politics 38.5, pp. $1020-41$.

- (2015b). "Legislative Organisation and its Determinants in European Parliamentary Democracies". West European Politics 38 (5), pp. 933-939. 
A Appendix

A.1 Results - Regression Tables 
Table A1: Hurdle model estimates (1811-2015)

\begin{tabular}{|c|c|c|c|c|c|c|c|}
\hline & \multicolumn{7}{|c|}{ Dependent variable: Sum of the number of sub-articles added, changed, and deleted } \\
\hline & $(1)$ & $(2)$ & $(3)$ & $(4)$ & $(5)$ & $(6)$ & $(7)$ \\
\hline \multicolumn{8}{|l|}{ Count component } \\
\hline Party control change & $\begin{array}{c}0.154 \\
(0.554)\end{array}$ & & & & $\begin{array}{l}-0.111 \\
(0.862)\end{array}$ & $\begin{array}{c}0.054 \\
(0.685)\end{array}$ & $\begin{array}{l}-0.044 \\
(0.648)\end{array}$ \\
\hline Majority to minority & & $\begin{array}{l}-2.212^{* * *} \\
(0.678)\end{array}$ & & & $\begin{array}{l}-2.099^{* *} \\
(0.968)\end{array}$ & $\begin{array}{c}-1.780^{* *} \\
(0.866)\end{array}$ & $\begin{array}{c}-1.416^{*} \\
(0.848)\end{array}$ \\
\hline Minority to majority & & $\begin{array}{c}0.874 \\
(0.953)\end{array}$ & & & $\begin{array}{c}0.177 \\
(1.269)\end{array}$ & $\begin{array}{l}-0.271 \\
(0.777)\end{array}$ & $\begin{array}{c}0.125 \\
(0.746)\end{array}$ \\
\hline Single-party to coalition & & & $\begin{array}{c}1.192 \\
(0.972)\end{array}$ & & $\begin{array}{c}1.123 \\
(1.184)\end{array}$ & $\begin{array}{l}-0.253 \\
(0.622)\end{array}$ & $\begin{array}{l}-0.148 \\
(0.443)\end{array}$ \\
\hline Coalition to single-party & & & $\begin{array}{l}-0.657 \\
(0.644)\end{array}$ & & $\begin{array}{l}1.218 \\
(1.607)\end{array}$ & $\begin{array}{l}2.222^{*} \\
(1.298)\end{array}$ & $\begin{array}{c}2.691^{* *} \\
(1.258)\end{array}$ \\
\hline Polarization change & & & & $\begin{array}{l}-21.948^{* * *} \\
\quad(7.396)\end{array}$ & $\begin{array}{l}-20.588^{* *} \\
(7.960)\end{array}$ & $\begin{array}{l}-15.967^{* * *} \\
(3.598)\end{array}$ & $\begin{array}{l}-16.223^{* * *} \\
(2.589)\end{array}$ \\
\hline $\begin{array}{l}\text { Number of session days } \\
\text { logged }\end{array}$ & & & & & & $\begin{array}{l}0.764^{* *} \\
(0.377)\end{array}$ & $\begin{array}{l}0.592^{* *} \\
(0.281)\end{array}$ \\
\hline $\begin{array}{l}\text { Number of articles at } t_{0} \\
\text { logged }\end{array}$ & & & & & & $\begin{array}{c}0.696^{* * *} \\
(0.203)\end{array}$ & $\begin{array}{l}-1.152 \\
(0.757)\end{array}$ \\
\hline Trend & & & & & & & $\begin{array}{c}1.748^{* * *} \\
(0.483)\end{array}$ \\
\hline Trend $^{2}$ & & & & & & & $\begin{array}{l}-0.561^{* * *} \\
(0.180)\end{array}$ \\
\hline Constant & $\begin{array}{c}1.613 \\
(25.331)\end{array}$ & $\begin{array}{c}2.242 \\
(6.660)\end{array}$ & $\begin{array}{c}1.768 \\
(18.131)\end{array}$ & $\begin{array}{l}2.783^{*} \\
(1.637)\end{array}$ & $\begin{array}{c}2.984^{* * *} \\
(1.057)\end{array}$ & $\begin{array}{c}-4.406^{* *} \\
(2.003)\end{array}$ & $\begin{array}{c}8.636 \\
(5.336)\end{array}$ \\
\hline \multicolumn{8}{|l|}{ Binomial component } \\
\hline Party control change & $\begin{array}{c}0.151 \\
(0.342)\end{array}$ & & & & $\begin{array}{c}1.034 \\
(0.642)\end{array}$ & $\begin{array}{c}1.146 \\
(0.764)\end{array}$ & $\begin{array}{l}1.291^{*} \\
(0.736)\end{array}$ \\
\hline Majority to minority & & $\begin{array}{c}0.006 \\
(0.584)\end{array}$ & & & $\begin{array}{l}-0.716 \\
(0.984)\end{array}$ & $\begin{array}{l}-0.841 \\
(1.012)\end{array}$ & $\begin{array}{l}-0.933 \\
(0.972)\end{array}$ \\
\hline Minority to majority & & $\begin{array}{l}-0.366 \\
(0.612)\end{array}$ & & & $\begin{array}{l}-0.101 \\
(0.897)\end{array}$ & $\begin{array}{c}0.030 \\
(0.865)\end{array}$ & $\begin{array}{c}0.008 \\
(0.953)\end{array}$ \\
\hline Single-party to coalition & & & $\begin{array}{l}-0.709 \\
(0.846)\end{array}$ & & $\begin{array}{l}-1.477 \\
(1.408)\end{array}$ & $\begin{array}{l}-1.852 \\
(1.758)\end{array}$ & $\begin{array}{l}-1.888 \\
(1.942)\end{array}$ \\
\hline Coalition to single-party & & & $\begin{array}{l}-0.438 \\
(0.871)\end{array}$ & & $\begin{array}{c}0.364 \\
(1.875)\end{array}$ & $\begin{array}{c}0.373 \\
(2.390)\end{array}$ & $\begin{array}{l}0.416 \\
(1.975)\end{array}$ \\
\hline Polarization change & & & & $\begin{array}{l}-0.220 \\
(2.806)\end{array}$ & $\begin{array}{l}0.506 \\
(3.022)\end{array}$ & $\begin{array}{c}0.201 \\
(3.632)\end{array}$ & $\begin{array}{c}0.721 \\
(3.791)\end{array}$ \\
\hline $\begin{array}{l}\text { Number of session days } \\
\text { logged }\end{array}$ & & & & & & $\begin{array}{c}0.626 \\
(0.380)\end{array}$ & $\begin{array}{c}0.600 \\
(0.454)\end{array}$ \\
\hline $\begin{array}{l}\text { Number of articles at } t_{0} \\
\text { logged }\end{array}$ & & & & & & $\begin{array}{c}0.934^{* * *} \\
(0.211)\end{array}$ & $\begin{array}{c}1.227^{* * *} \\
(0.376)\end{array}$ \\
\hline Trend & & & & & & & $\begin{array}{l}-24.277^{* *} \\
(10.141)\end{array}$ \\
\hline Trend $^{2}$ & & & & & & & $\begin{array}{l}2.826^{* *} \\
(1.199)\end{array}$ \\
\hline Constant & $\begin{array}{l}-0.205 \\
(0.205)\end{array}$ & $\begin{array}{l}-0.105 \\
(0.205)\end{array}$ & $\begin{array}{l}-0.150 \\
(0.193)\end{array}$ & $\begin{array}{l}-0.132 \\
(0.197)\end{array}$ & $\begin{array}{l}-0.162 \\
(0.233)\end{array}$ & $\begin{array}{c}-7.513^{* * *} \\
(1.587)\end{array}$ & $\begin{array}{l}42.443^{* *} \\
(19.666)\end{array}$ \\
\hline $\mathrm{AIC}$ & 1211.553 & 1197.825 & 1213.876 & 1148.695 & 1149.6 & 1050.834 & 1026.489 \\
\hline
\end{tabular}




\section{A.2 Robustness: Parliament \& Session Jackknifing}

Figures A1-A4 plot changes in the p-values associated with the effect for key variables for the re-estimation of model (7) in Table A1 with parliament jackknifing (left panel), and session jackknifing (left panel). Black lines represent legislatures/sessions without which the confidence level drops below 90 percent $(p>0.1)$. Robustness plots are only provided for variables that were found to have a statistically significant effect. These include changes in party control in the binomial component, and majority-to-minority disturbances, changes from coalition to single-party government, and alterations to polarization in the count component, see Section 4. Taking the 0.1 significance level as a benchmark, the effect of the first variable retains significance in all but 1, while and the latter three lose significance in 50, 6 and 0 cases respectively. ${ }^{23}$

Similarly our findings for the change in party control are less influenced by leaving out individual sessions, where its effect remains statistically significant to at least the 90 percent confidence level in all 233 sessions but 1. Again, the effect of majority-to-minority changes is sensitive to jackknifing, with its p-value rising above 0.1 in all sessions. Meanwhile, our coalition to single-party government predictor loses statistical significance in 6 cases, while polarization maintains significance at the highest level in all cases.

\footnotetext{
${ }^{23}$ The maximum p-values obtained in the sensitivity analyses for the effect of party control change is 0.12 , which is still relatively low.
} 


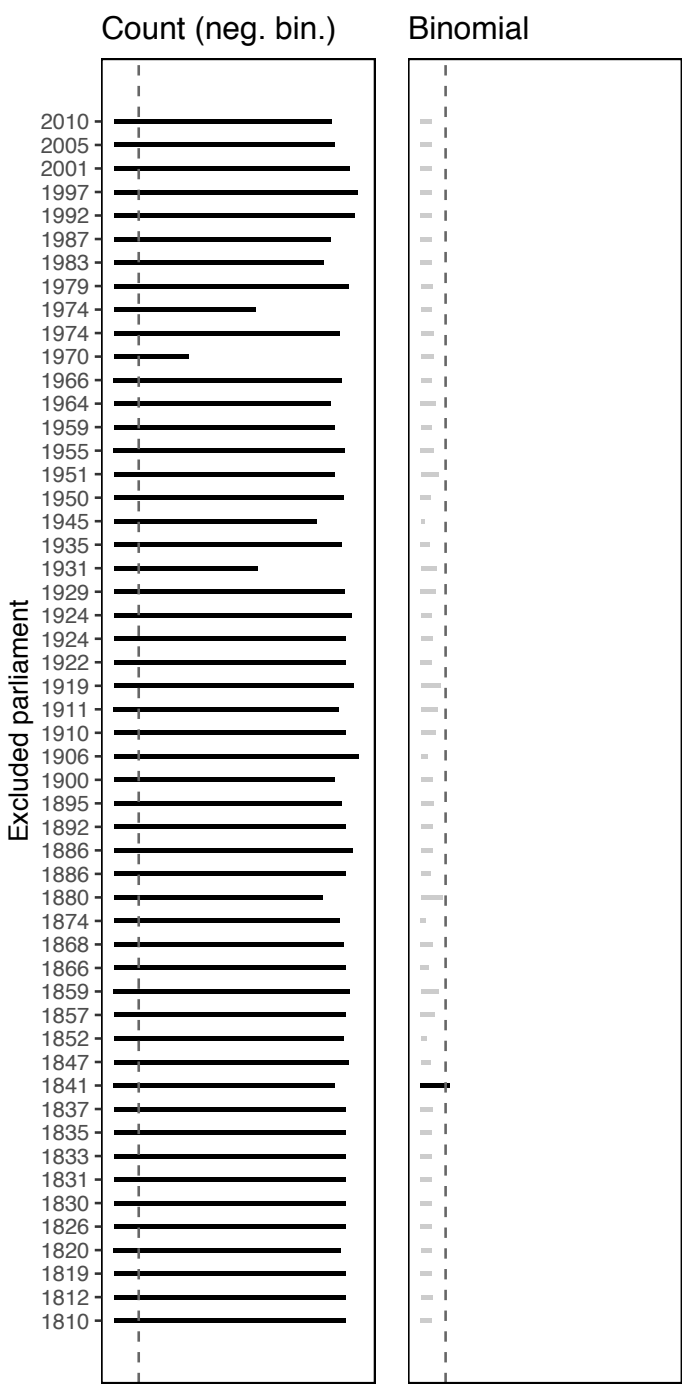

Parliaments

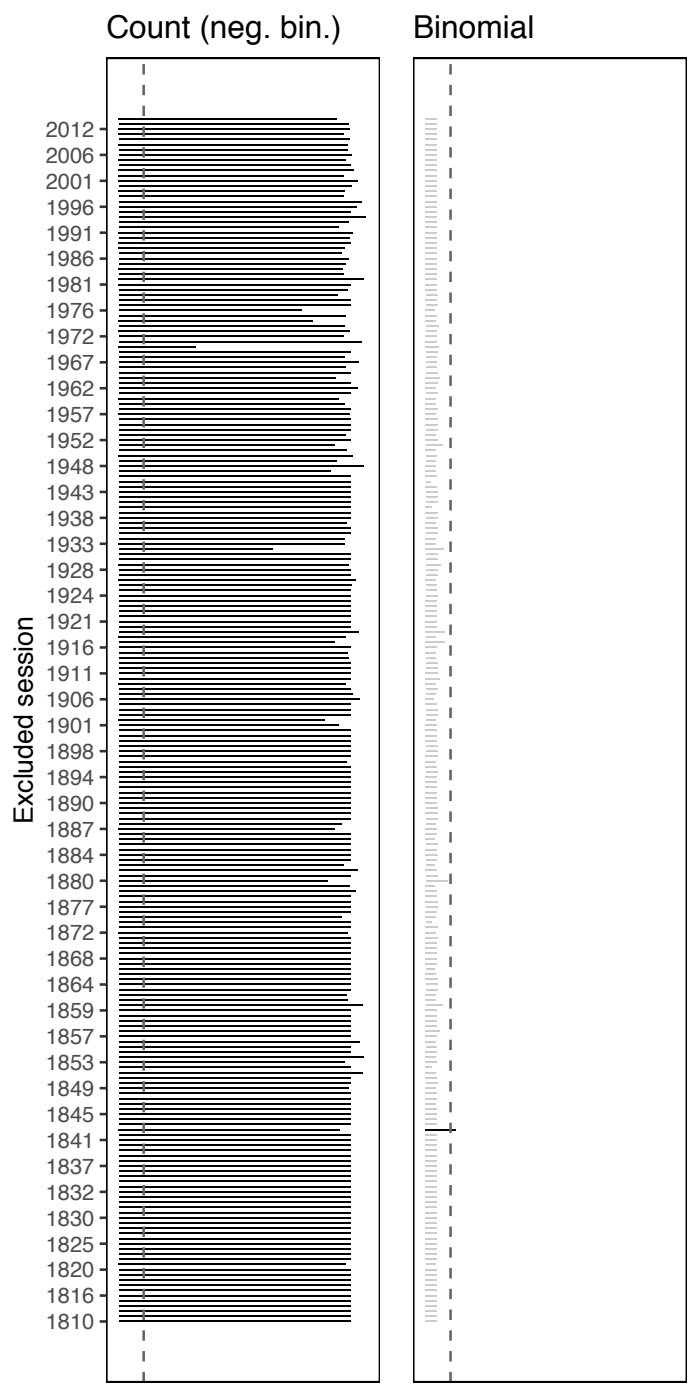

Sessions

Figure A1: Robustness for Party Control Change 


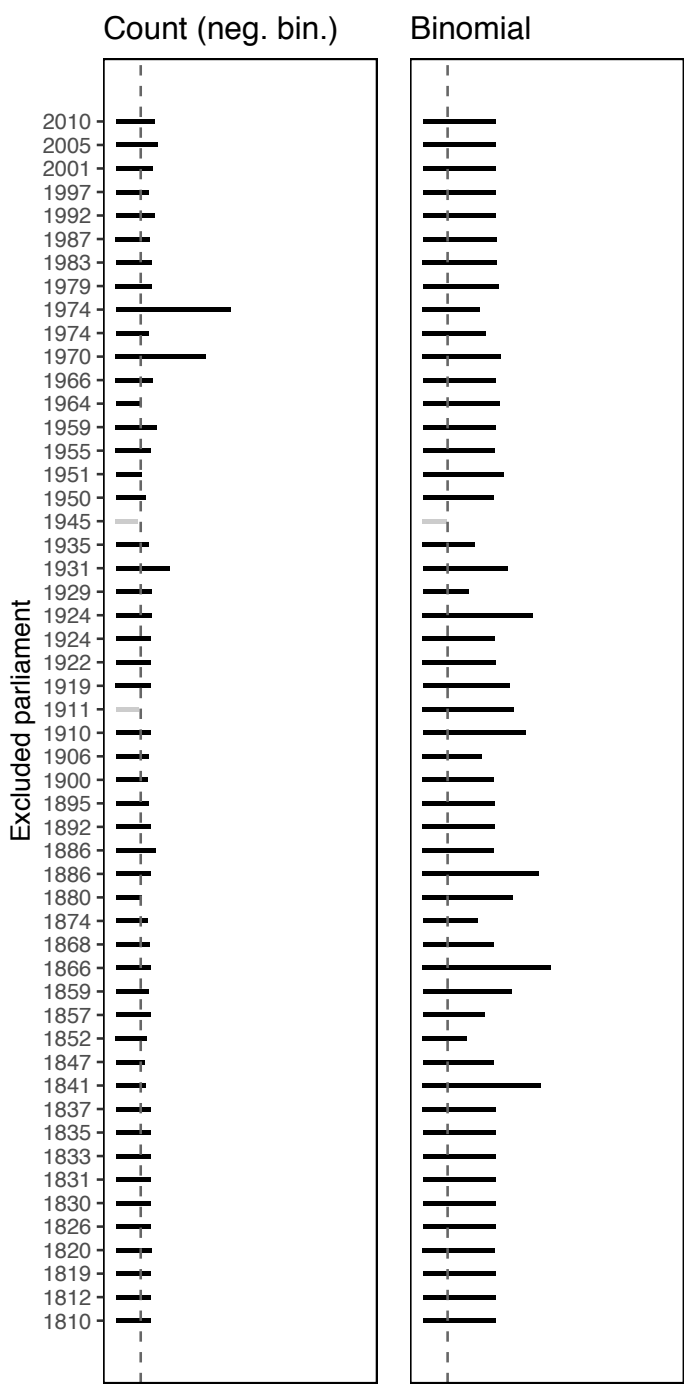

Parliaments

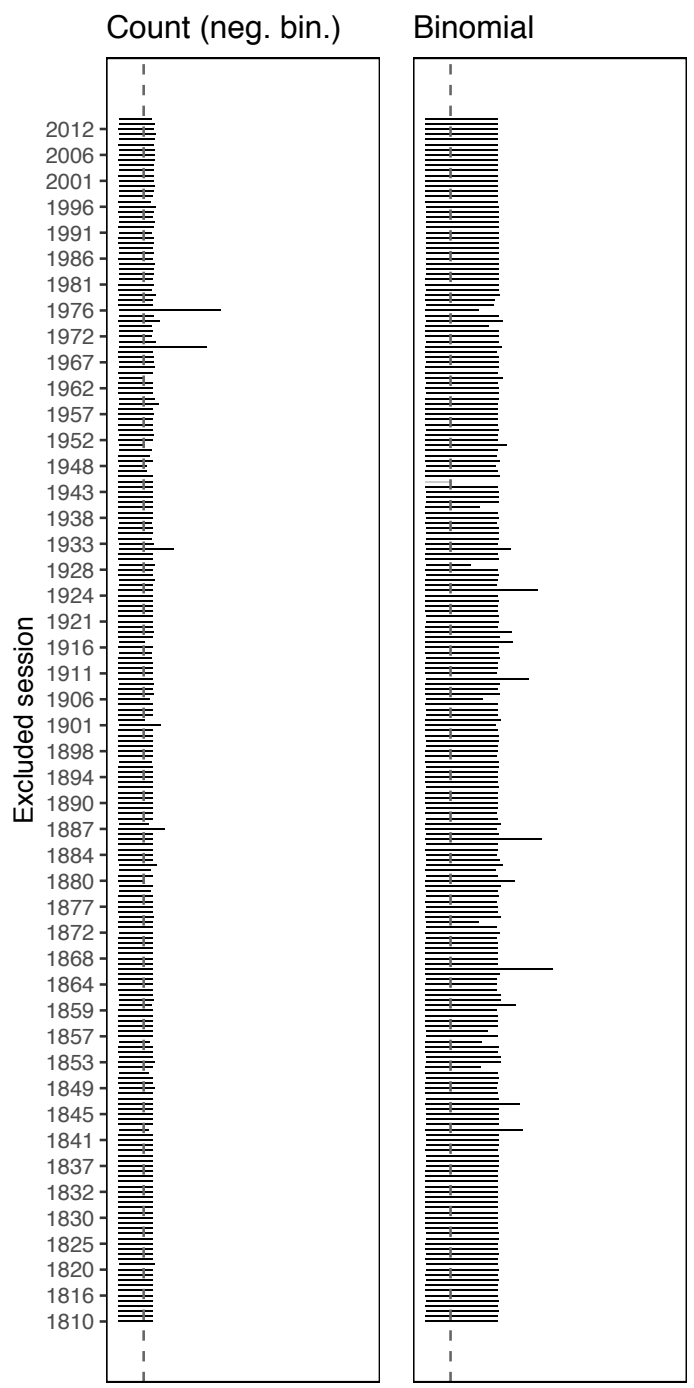

Sessions

Figure A2: Robustness for Majority-to-Minority Change 


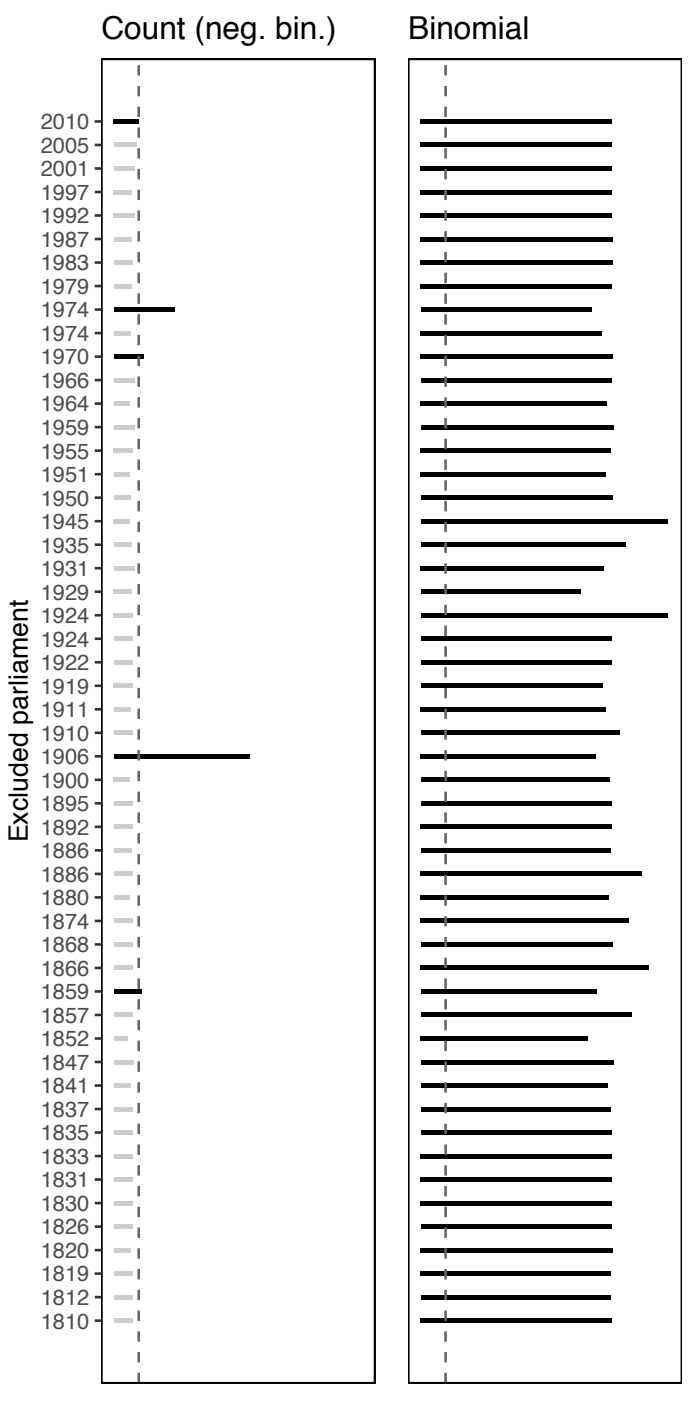

Parliaments

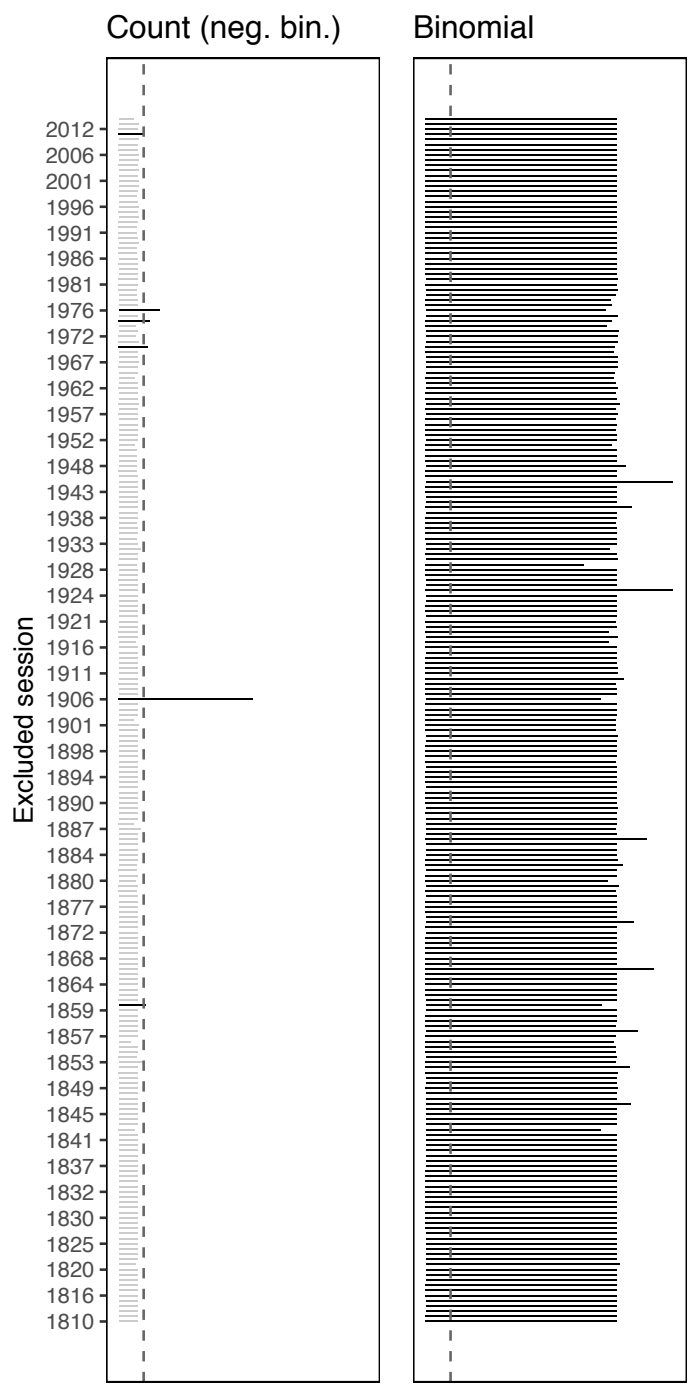

Sessions

Figure A3: Robustness for Coalition to Single Party Change 


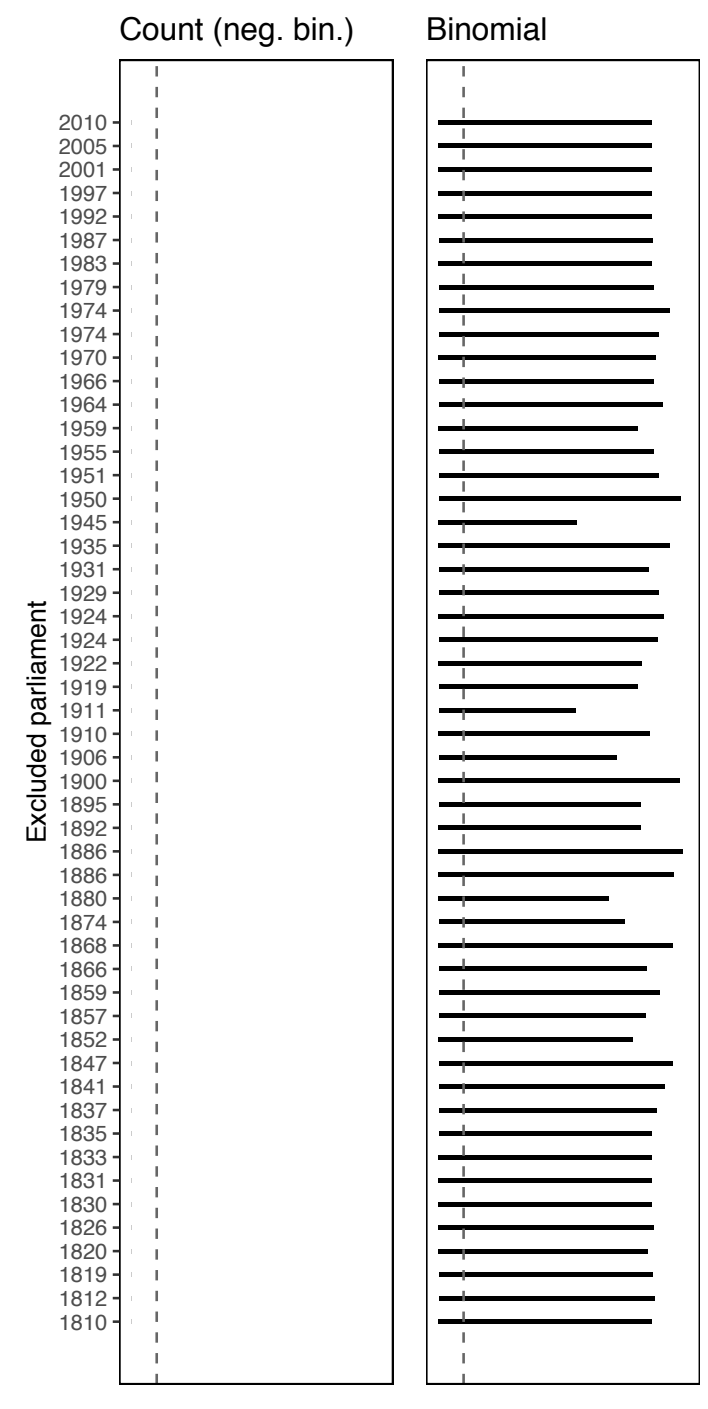

Parliaments

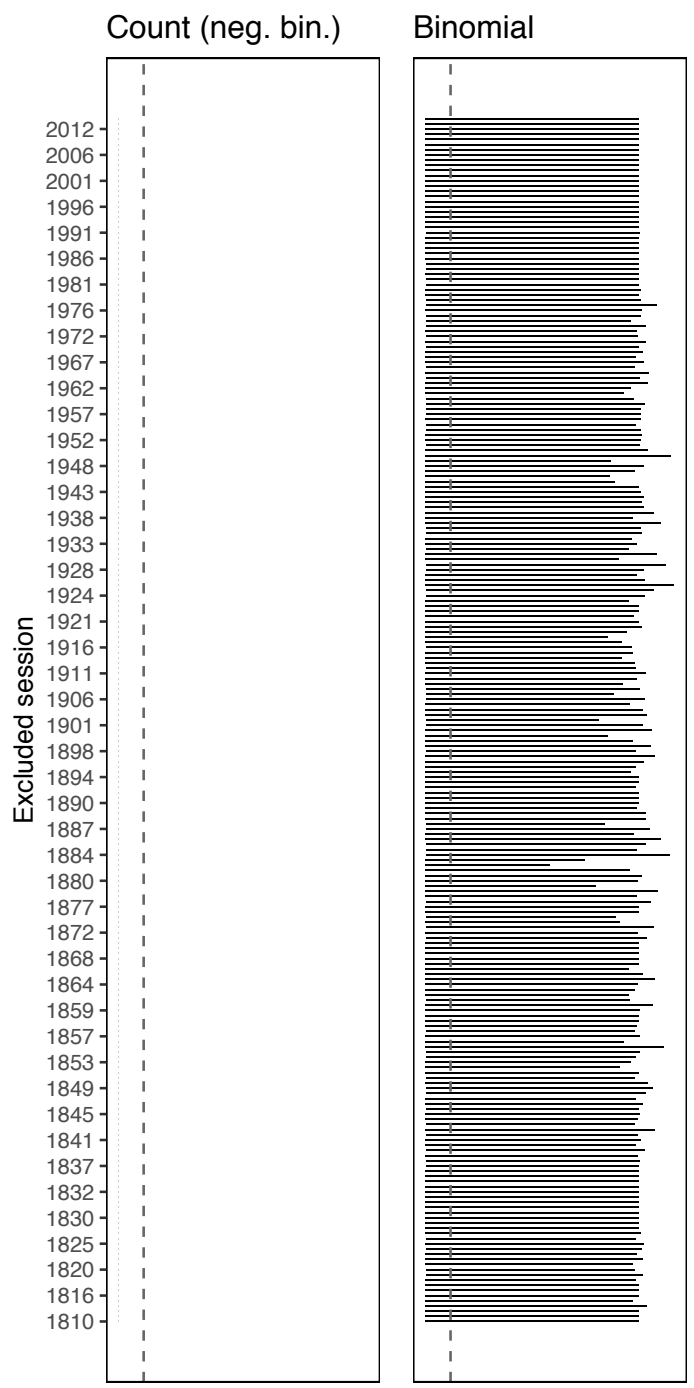

Sessions

Figure A4: Robustness Plot for Polarization Change 